\title{
Suresh C. Ameta and Rakshit Ameta (Eds.): Solar Energy Conversion and Storage. Photochemical Modes
}

\author{
Ken Jones ${ }^{1}$
}

(C) Springer-Verlag Berlin Heidelberg 2016

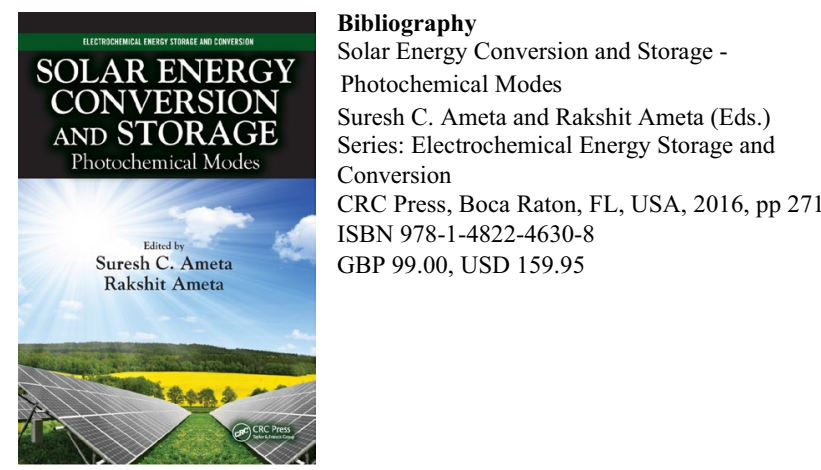

Countries and geographic areas with a surplus of particular energy sources will naturally concentrate on the most easily realisable. This compilation is no exception. Twentyfour of the thirty-one papers emanate from the Indian subcontinent, and three are from the West.

Relevance and overall quality of the research are first assessed, followed by its contribution to the science. In common with almost all books on renewable energy, very little attempt has been made to quantify potential economic gains from the described technology. It is a constant disappointment that anyone reading these editorial selections of the latest research work is not provided with a benchmark of its actual value, relative or otherwise. The best benchmark is surely that most basic and vital of measurements; can energy resulting from this research be produced at a lower cost than that currently available? However much environmentalists may claim that economic

Ken Jones

chromatographia@springer.com

1 Knutsford, Cheshire, UK issues are secondary, the unreal world of constant subsidy is unsustainable. But why are subsidies required, when it can be demonstrated that home-installed solar energy can be produced for around US $2 \mathrm{c} / \mathrm{kW}$ compared to grid supply averaging $13 \mathrm{c} / \mathrm{kW}$ ? This enormous economic advantage at the point of use is rarely if ever discussed. It would be refreshing if at least one set of editors, when compiling their renewable energy book, would write a comparative summary chapter on the relevance of its content to the real world.

A partial answer to the question above is the economic storage of unused electricity when generated by solar power. Storage battery research is accelerating hugely. Lithium/sulphur technology has already doubled electrically driven vehicle (EDV) single-charge distances from 150 to 300 miles. When combined with a manufacturing scale of 1 million units (currently a mere 10,000 units), application of the six tenths rule indicates that battery costs, the largest cost element of EDVs, will fall by $75 \%$. Adoption of this technology in home systems is too obvious to miss. Widespread adoption of realistically costed batteries with 25 -year plus lifetime use will surely revolutionise home-installed solar energy in all parts of the world. As always, if a non-subsidised solar panel/battery combination can be shown to produce lower cost electricity than the grid, there will be no need for badly designed legislation that appeases environmentalists but at such high cost to the populace in general.

Unless involved directly in one of the specific fields described, there appears little to be gained from purchasing this book. For students, it is disjointed, and for post graduates, the research described can equally be read through published papers. The chapter on hydrogen as a fuel seems to have been added for completeness; although seductive in concept, its attractions are limited. 